\title{
ERA - E-learning readiness Analysis A eHealth case study of e-learning readiness
}

\author{
J. Schreurs \\ Hasselt University, Diepenbeek, Belgium \\ Jeanne.Schreurs@uhasselt.be \\ George Sammour \\ Hasselt University, Diepenbeek, Belgium \\ George.sammour@uhasselt.be \\ U. Ehlers \\ University of Duisburg-Essen, Germany \\ ulf.ehlers@web.de
}

\begin{abstract}
Electronic learning is seen as a good solution for organisations that deal with fast changing knowledge and for reducing the cost of training. E-learning is a good opportunity for companies but needs to be well prepared because it takes often high investment costs. That is why it is important for a company to know if it is e-ready. E-readiness is already well covered in literature and several models are suggested. We used these models to develop an e-learning readiness measurement instrument and questionnaire. We used our instrument to check whether the Flemish hospitals were e-ready for e-learning.
\end{abstract}

\section{Introduction}

The promises of e-learning for organisations are manyfold. Too often they fail to take effect. The reason is a not sufficient readines to take up e-learning in an organisations and absob the innovation effects coming along with it. In this paper we suggest e-learning readiness as a key factor influecing the uptake of e-learning in organisations. We present ERA an e-learning readyness analysis toool and discuss results its application from a case study in the healthcare sector.

In the globalised world of the 21st century, organisations are confronted with a challenging economic competition. Employees need to be equipped with new competences to adapt to constantly changing work and life conditions in knowledge-based economies and societies. Organisations are aware of the value of knowledge and learning for their continual development and for the acquirement of a competitive advantage, which relates to innovation and fulfilment. Especially the healthcare sector is a fast changing environment and it is clear that its performance depends on the ability of staff to update their competences fast in order to adapt to a constant changing environment (S.Psycharis 2005, Bernhardt et al., 2003). Looking at e-learning in today's organisations, it can be defined as the delivery of instructional content or learning experiences enabled by electronic technology and it is one of the major innovations that is diffusing corporate settings. E-learning requires that the learners use the internet, collaborate with peers and interact with the trainer for support. Experienced e-learners can even use technology to monitor their training and ultimately become responsible managers of their own personal and career development. The number of e-learning initiatives in corporate training scenarios is steadily increasing. Reasons are related to the cost of training and reports show that e-learning contributed to saving travel costs and downtime for workplaces. Advantages such as asynchronous training, training at individual pace, just-in-time training, and cost-effectiveness lure organizations to e-learning (Powell 2000). The opportunity to learn via technology presents an exciting prospect to train even learners with little previous access to computer-based training. E-learning is a good opportunity for 
organisations that deal with fast changing knowledge but companies needs to be well prepared because it takes often high investment costs.

\section{Introducing e-learning readiness}

Organizations have to be ready to adopt e-learning and benefit from its advantages. Such e-readiness can be defined as "how ready the organisation is on several aspects to implement e-learning". E-learning-readiness should be determined before organizations introduce e-learning. Readiness includes learners' ability to adapt to technological challenges, collaborative training and synchronous as well as asynchronous self-paced training. It also depends on their motivation and their discipline to learn in a self-driven mode and to respond to online instructions. E-readiness makes up the e-maturity of the organization which also is represented in the readiness of learners. It includes the availability of infrastructure, clear training objectives, trainer support and guidance and knowledgeable leadership. Therefore, e-learning not only requires readiness from the learner but also from the trainer and the organization to successfully engage e-learning (Bowles 2004).

\subsection{Strategy to improve learners’ online experience}

In the study of Ipsos Mori (Ipsos Mori 2006), key components of e-learning readiness have been identified: social context, content delivery, technology access, learning style, collaboration capacity, organisational learning environment and personal motivation. Over two-thirds of employees would like to see their organisation make more use of e-learning. Three in four feel e-assisted training could be useful to them as trainers or to other trainers in their organisation. Employers who are more sceptical say that they are limited by resources; half feel they don't have the budget while three in five believe that employees will just not be interested. The key reason why some employers are sceptical about the potential of e-learning is that of technical resources. One of the main barriers to effective elearning is the lack of accessible computers at the workplace. To improve learners' online experience, strategies need to be found that address the 5 areas of difficulty encountered by people which diminish the quality of their experience and may make people less inclined to e-learning. (Ipsos MORI 2006). The five areas of difficulty are the technical means, autonomy in web use, e-skills, level of social support, variation in motivation Some cross-cutting components are influencing how people perceive barriers to e-learning and therefore how ready they feel they are to participate in it Influencing components are the organizational culture, self-belief, computer competence and computer training.

\subsection{E-readiness assessment}

Literature on organizational readiness for e-learning provides managers with questions, guidelines, strategies, models and instruments for assessing the readiness of their companies. E-readiness can be assessed by evaluating an individual's technical experience and competency to interact with computers. This competency should be supported by the individual's capability to direct his or her own training through appropriate knowledge, skills, attitudes, and habits. Aydain and Tasci (Aydin, 2005) suggests a questions tool with 7 categories: human resources, learning management system, learners, content, IT, finance and vendor. Another categorization results from Chapnic (Chapnic 2005): psychological, sociological, environmental, HR, financial readiness, technological skill (aptitude), equipment, content readiness.

\subsection{Model to measure e-learning readiness}

How to find a comprehensive concept to measure the e-readiness of organisations? Which criteria can be included? If we examine the models described above closely we see certain common parameters that always come back. Psycharis suggests three large categories (Psycharis 2005): resources, education and environment. Each category contains certain criteria. In the category resources the technological readiness, the economic readiness and the human resources readiness are investigated. Education means the readiness of content and the educational readiness. Environment includes entrepreneurial readiness, leadership readiness and readiness of culture. 
- Resources: First of all we want to investigate the technological readiness, about the available technological systems that are provided and the way they are used. The economic readiness examines the willingness of the organisation to invest in e-learning. Implementing e-learning brings along large costs and the organisation needs to be prepared to make the necessary investments in infrastructure but also foresees a degree of administration support. The human readiness refers to the knowledge and the skills of the employees being the e-learners. An important question is if staff has the necessary basic skills and if they do feel at ease with used technology, necessary investments in infrastructure but also foresees a degree of administration support. The human readiness refers to the knowledge and the skills of the employees being the e-learners. An important question is if staff has the necessary basic skills and if they do feel at ease with used technology.

- Education: Whether or not an organisation is ready from an educational point of view will be determined by the measurement of the readiness of the content. Is the educational content easily available, is it structured good and is it reusable? But also the educational readiness is important. It is about the learning styles and the educational needs of the employees.

- Environment: The criteria of this category are the entrepreneurial readiness and the readiness of the culture. So the Flemish hospitals of our case all have their own authority on decision making on how how they train their staff.

\subsection{Building ERA - The E-learning readiness analysis instrument}

Studying the already existing theory and using our insights of e-learning and quality aspects of e-learning we developed an e-learning readiness measurement instrument (Schreurs 2008). We developed a structure for the instrument and developed a set of questions based on our self assessment quality questionnaire. This questionnaire can slightly be changed, and adopted according to the sector in which it is used - if necessary.

\section{Learner characteristics \\ - ICT skills of the trainees \\ - Motivation for use of e-learning of the trainees \\ - Do they have a preferred learning style? (prefer presentations including audio, video, ....)}

2. Available facilities for e-learning

- ICT aspects / infrastructure

- $\quad$ Learning management system

\section{Management}

- Investment in physical environment

- Organization of e-learning in-house

- Investment in good user systems

- Investment in e-learning infrastructure

- Learning time during working hours?

4. E-learning solutions/ courses /processes

- Information about available course

- ICT aspects

- $\quad$ Support learning activity

- Maintenance of systems

- Organization of learning activity itself

- $\quad$ Support of the learner

\section{Applying ERA to hospitals: the Agfa case}

A study on the adoption of e-learning for public health nurse continuous education showed an affirmative intention towards adopting e-learning as their way of continuing education (Shu $\mathrm{Yu}$ et al. 2006). Reasons for adopting e-learning include achieving lifelong learning, fulfilling personal interests, the orientation on concrete job needs, demands for information diversity, flexibility in time and space, the possibility of self-regulatory learning, cost-effectiveness, and less impact on family duties. Reasons to reject e-learning include poor computer literacy, lack of personal access to computers with and without internet access, heavy workload, lack of motivation, low selfcontrol. On the whole, employees are keen to see e-enabled training and staff is interested in e-learning. Three in five employees think e-learning is a practical option in their own organisation (ibid.). Healthcare workforce is e-ready.

\subsection{The case: eHealth services of Agfa}

In collaboration with the company Agfa healthcare, we were investigating the e-learning readiness of 10 Flemish hospitals being the customers of Agfa. Agfa HealthCare is a leading provider of integrated IT solutions and state-of- 
the-art diagnostic imaging for hospitals and other healthcare centers. The mission of Agfa Healthcare is to support the transformation process to ICT solutions being improving the medical care services of the hospitals. Recently Agfa Healthcare provides e-learning services to its customers, the hospitals. All ICT solutions will be complemented with an optional e-learning component. The e-learning component can be accessed via an e-learning portal of Agfa. By the way the hospital can also change from traditional classroom learning to e-learning. The e-learning course functions also as a help tool afterwards.

\subsection{Applying ERA: An eHealth case}

Agfa is convinced of the advantages of using their e-learning solution for the hospitals, replacing the traditional classroom learning - but are hospitals ready to change? For the analysis we first selected the relevant criteria from our e-learning readiness measurement instrument We developed a questionnaire of 80 questions that should assess the e-readiness of the hospitals in several areas. The development of the questionnaire has been based on earlier mentioned criteria in combination with quality questionnaires of e-learning which we developed earlier (Schreurs et al. 2008). We checked first for the preferred situation by the doctor radiologist, the head of nursery of the department and the ICT director. Secondly we asked to do a self-assessment of their skills, motivation, experiences, and alike. Thirdly we asked for the evaluation of the hospital ICT infrastructure to be used for e-learning. Furthermore we also asked a judgement from AGFA in which way they are facilitating the e-learning application for the hospital.

Table 1: e-learning readiness measurement instrument, measuring e-readiness in a hospital

\begin{tabular}{|c|c|c|c|c|c|c|c|c|}
\hline \multirow[t]{2}{*}{ Criteria /subcriteria } & \multicolumn{3}{|c|}{$\begin{array}{l}\text { How important for } \\
\text { you (scale: } 1 \text { to } 4 \text { ) }\end{array}$} & \multicolumn{2}{|c|}{$\begin{array}{c}\text { Evaluation of } \\
\text { skills level of } \\
\text { learner } \\
\text { (scale: } 1 \text { to } 4 \text { ) }\end{array}$} & \multicolumn{2}{|c|}{$\begin{array}{c}\text { Quality of e- } \\
\text { learning } \\
\text { facilities } \\
\text { (scale: } 1 \text { to 4) }\end{array}$} & \multirow{2}{*}{$\begin{array}{c}\begin{array}{c}\text { Evaluation } \\
\text { facilities } \\
\text { by AGFA }\end{array} \\
\text { AGFA } \\
\end{array}$} \\
\hline & doctor & nurse & ICT & doctor & nurse & ICT & $\begin{array}{l}\text { Mgmt } \\
\text { Doctor }\end{array}$ & \\
\hline \multicolumn{9}{|l|}{ Enabling Learning Resources } \\
\hline \begin{tabular}{l|lrl}
$\begin{array}{l}\text { Information } \\
\text { opportunities }\end{array}$ & on available learning \\
\end{tabular} & $\mathrm{x}$ & $\mathrm{x}$ & & & & & & $\mathrm{x}$ \\
\hline \multicolumn{9}{|l|}{$\begin{array}{l}\text { The electronic online Learning } \\
\text { Environment }\end{array}$} \\
\hline \begin{tabular}{l|l} 
& ICT and the learning system \\
\end{tabular} & & & $\mathrm{x}$ & & & $\mathrm{x}$ & & $\mathrm{X}$ \\
\hline $\begin{array}{l}\text { System functions facilitate learning } \\
\text { activities }\end{array}$ & & & $\mathrm{x}$ & & & & & $\mathrm{x}$ \\
\hline \begin{tabular}{l|l|} 
& Maintenance of facilities \\
\end{tabular} & & & $\mathrm{x}$ & & & & & $\mathrm{X}$ \\
\hline $\begin{array}{l}\text { The physical learning environment } \\
\text { provided for online session }\end{array}$ & $\mathrm{x}$ & $\mathrm{x}$ & & & & & $\mathrm{X}$ & \\
\hline \multicolumn{9}{|l|}{ Investment in e-learning solutions } \\
\hline $\begin{array}{l}\text { Investments in local central ICT learning } \\
\text { infrastructure for implementation of e- } \\
\text { learning }\end{array}$ & & & $\mathrm{x}$ & & & & $\mathrm{X}$ & \\
\hline \multicolumn{9}{|l|}{ Learners in this new learning environment } \\
\hline ICT skills of learners & & & & $\mathrm{x}$ & $\mathrm{x}$ & & & \\
\hline Motivation of learners & & & & $\mathrm{x}$ & $\mathrm{x}$ & & & \\
\hline Learning styles of learners & & & & $\mathrm{x}$ & $\mathrm{x}$ & & & \\
\hline \multicolumn{9}{|l|}{ Enabling Learning Processes } \\
\hline E-learning activities & $\mathrm{X}$ & $\mathrm{x}$ & $\mathrm{x}$ & & & & & $\mathrm{X}$ \\
\hline \begin{tabular}{l|l} 
& Course progression \\
\end{tabular} & & & & & & & & \\
\hline Teaching approach/Course design & & & & & & & & \\
\hline $\begin{array}{l}\text { Personalising the learner's e-learning } \\
\text { course }\end{array}$ & & & & & & & & \\
\hline \begin{tabular}{l|l} 
& Personalising your own learning \\
\end{tabular} & & & & & & & & \\
\hline Learner Support & $\mathrm{x}$ & $\mathrm{x}$ & $\mathrm{x}$ & & & & & $\mathrm{x}$ \\
\hline \begin{tabular}{l|l} 
ICT Support \\
\end{tabular} & & & & & & & & \\
\hline \begin{tabular}{|l|l|} 
& Online support \\
\end{tabular} & & & & & & & & \\
\hline The resulting Learning Results & & & & & & & & \\
\hline Knowledge Increase & $\mathrm{x}$ & $\mathrm{x}$ & & & & & & \\
\hline Using skills learned & $\mathrm{x}$ & $\mathrm{x}$ & & & & & & \\
\hline
\end{tabular}




\subsection{Results: E-learning readiness in hospitals}

The results of our analysis of 10 hospitals were quite homogeneous and will be reported in summary below, referring to general aspects as well as specific experiences from the case study.

- Learner characteristics: Most employees don't have experience using an e-learning course, although most of them work regularly with pc and have knowledge of the standard packages. It is very important that the first time they use e-learning, they will be guided and they prefer a classroom session organised in advance to coach and enhance the use of the system. It is recommendable that the key-users will be thoroughly coached when they have no experience with e-learning. The learners are not more motivated for e-learning, than for a traditional course. It can be explained by the fact that most of them still have no experience with e-learning. It is an opportunity for Agfa to clarify the advantages of an e-learning solution. On point of the preferred learning styles, we see that video fragments are regarded necessary in an e-learning course and the insertion of simulation modules in the e-learning system creates a large surplus value. So we can say that if those two items are integrated in the system, the readiness of the users will increase. However results also show that they don't prefer audio above written documents.

- Available facilities for e-learning: First we consider the ICT aspects and their scores. We checked the expected ICT situation, the current situation and the AGFA approach. A first remarkable result is the similarity between the expected situation of the hospitals and the solution for facilitating e-learning as delivered by AGFA. The results from AGFA can be seen as the requirements of ICT infrastructure of the hospitals. We see a good match between the expected situation and the prospected situation by Agfa. Though there is a discrepancy between thye expected situation and the actual situation. Hospitals are aware that the current situation of the ICT infrastructure is often not sufficient to meet the requirements. Some additional investments are required. We find another remarkable result with the underlying system functions to facilitate e-learning. There is a great discrepancy between the required underlying system functions (average score of 3.2) and the way Afga wishes to facilitates them (average score of 1.0). Agfa has to consider to built in underlying system functions. The same results are denoted for the maintenance of ICT facilities: an average score of the expected situation resulted in 4.0 which is remarkable higher than the average score of 2.5 of AGFA. The reason for the difference lies mainly in the range of scores of the indicator : adjustment of the learning system to new versions of system software. Also here Agfa should consider the incorporation of this facility in the packet.

- Management: The wishes of all staff are quite similar as for the physical aspects. The expectations are rather high. Which is good in the case for Agfa because their physical learning environment is already on a high level. The duration of the learning hours in working time is preferable above the willingness to work at home. The current ICT infrastructure isn't good enough in most cases. ICT is fairly prepared to make investments to upgrade to the necessary level to making e-learning possible and successful

- E-learning solutions/courses: On the information of training supply they all agreed, the composition of the elearning packet must be clear. Accordingly Agfa can satisfy his customers by composing clearly structured packet. The personalisation of the e-learning course gives a remarkable difference. Hospitals want a reasonable personalisation of the course in contrast with Agfa, who clearly not wishes to incorporate personalisation. If Afga would add to the readiness to e-learning of the hospitals it should consider personalisation. The self management of the learning process gives also a difference between hospitals and Agfa but in the opposite direction. On this matter Agfa thinks it is very important in contrast with the hospitals who rate it low. Support of the trainee is considered important for all persons in hospital this for as well ICT as online support; Also here Agfa considers this as being of minor importance. It creates again a new opportunity for Agfa to add to the readiness of the company if the wish to compromise in this matter. The learn results that are put forward being enlargement of knowledge and apply what is taught is important to radiologist and they expect a thorough knowledge. Case versus results found in the literature.Out of the literature we found some findings on readiness to e-learning in the social care sector. SCIE concluded seven components of good e-learning delivery from a study of international e-learning experiences. The results suggest that without these components put in place by organisations, barriers will form and inhibit the e-learning experience. We will first refer to them short and then compare them with the result of our case study.

- Situational component: This component includes elements of basic 'know how', but goes beyond this in that it includes elements that influence how e-learning is facilitated within an organisation. In the reported case most employees did not have experience using an e-learning course, although most of them work regularly with pc 
and have knowledge of the standard packages, as stated earlier it is very important that the first time they use elearning, they will be guided well.

- Content suitability component: The subject materials that are made available to e-learners are important too. In the reported case the results all agreed upon that the composition of the e-learning packet must be clear. Hospitals value high the presentation of the course, the progress of the course, the personalisation of the course and in a lesser extent the self-management of the process

- Technological component: There are three distinct technological elements which organisations need to address if they are to be ready to deliver e-learning. These include the hardware available to staff, the internet connectivity and how flexible the system is to engage with all the webbased material. In the reported case the physical conditions seem to be evaluated of great importance to the employees and score in general well in Flemish hospitals

- Learning style component: How well an organisation matches the learners it has to diversify the types of training and learning resources it can offer. In the reported case it became apparent that if taking a look at the preferred learning styles in our questionnaire, we see that video fragments are regarded necessary in an elearning course and the insertion of simulation modules in the e-learning system creates a large surplus value. So we can say that if those two items are integrated in the system, the readiness of the users will increase.

- Instructional and network component: This component identifies the elements required for a collaborative elearning approach. In the reported case supporting system facilities are wanted by the hospitals but are not facilitated by supply. Here an opportunity can be taken by supply to increase the readiness.

- Organisational component: Here we consider the organisational culture or attitude to e-learning, the learning environment it fosters, the applicability of training to the work of the organisation and the way in which it evaluates the impact of training. In the reported case this component wasn't of great importance for our research because the decision on whether and how the training is organised was a decision of authorised staff employee.

- Personal component: The organisation's ability to influence staff motivation. In the reported case e-learning is not yet be seen as being more motivational then traditional learning. So the advantages of e-learning have to be well pointed out for. A challenge for the Flemish market;

\section{Conclusions}

Everyone is aware that e-learning can offer advantages. Obstructions for implementing can be among others high costs and because of these obstructions, there is still a lot of reservation towards e-learning. An organisation can check how ready it is on several aspects to implement e-learning, this is called e-readiness. In this paper we wanted to see whether the Flemish healtsector was e-ready. The theory offers several models and approaches. We used our own to see whether the results of the research corresponded with the theory. It seems results follow theory but that it needs efforts from both sides to increase the readiness. E-readiness requires a team effort from as well demand as supply, from trainer as trainee.

\section{References}

Aydin, C.H. \& Tasci, D. (2005). Measuring readiness for e-learning: reflections from an emerging country. Educational Technology \& Society, 8 (4), 244-257.

Bernhardt et al., 2003: J.M.Bernhardt, C.W.Runyan, I.bou-saada and E.M.Felter: implementation and evaluation of a web-based continuing course in injury prevention and control. Health promotion Practice 4(2) (2003), pp 120-128.

Bowles M. (2004): Relearning to e-learn: strategies for electronic learning and knowlzdge, Melbourne University Press.

Chapnic,S. (2005). Are you ready for e-learning? Learning Circuits: ASTD’s Online Magazine All abouit e-learning.

Chorng-Shyong, Jung-Yu, Yi-Shun: Factors affecting engineers' acceptance of asunchronous e-learning systems in high-tech companies. Information \& management, Vol 41, Issue 6, 2004, pages 795-804.

H.B.Moolman, S.Blignaut: Get set! E-ready, ...e-learn! The e-readiness of warehouse workers. Technology \& Society, 11 (1), 168-182.

Mungania, P. The Seven E-Learning Barriers Facing Employees. The Masie Centre, 2003.

E-Readiness in the Social Care Sector

Powell, G.C. (2000) Are you ready for web-based training? Educational Technology \& Society, 3 (1), 52-55. 
Sarantos Psycharis ( 2005 ) Presumptions and actions affecting an e-learning adoption by the educational system. Implementation using virtual private networks, Eurodl (http://www.eurodl.org/materials/contrib/2005/Sarantos_Psycharis.htm)

SCHREURS, Jeanne; Husson, A.M.; Merison, B.; Morin, E. \& Van Heysbroeck, H. (2008) SEVAQ: a unique multi-functional tool for assessing and improving the quality of e-courses. In: International Journal of emerging technologies in learning (iJET), 3(1).

Shu Yu, I-Ju Chen, Kuei-Feng Yang, Tze-Fang Wang, Lee-Lan Yen: A feasibility study on the adoption of e-learning for public health nurse continuing education in Taiwan. Nurse Education today, Vol 27, Issue 7, 2007, pages 755-761.

Study from Ipsos MORI; Social Care Institute for excellence. E-readiness in the social sector. December 2006. 